\title{
ARQUEOLOGIA DO BAIXO SUL DA BAHIA: RESIDÊNCIAS RURAIS DO SÉCULO XIX EM ITACARÉ, BAHIA, BRASIL
}

Carlos Alberto Santos Costa*

Fabiana Comerlato**
RESUMO: No presente texto apresentamos os resultados das intervenções arqueológicas realizadas em duas residências rurais do século XIX, identificadas na bacia do Rio de Contas, Bahia, durante a construção da rodovia BA-001 (Camamu e Itacaré). Para tanto, serão disponibilizados os dados arqueológicos e a interpretação dessas unidades habitacionais como integrantes de um sistema de controle territorial difuso da paisagem.

Palavras-chave: arqueologia; residências rurais; século XIX; controle territorial difuso da paisagem; bacia do rio de Contas.

ABSTRACT: In this paper we present the results of archaeological interventions in two rural residences of the 19th century in the Rio de

* Universidade Federal do Recôncavo da Bahia carloscosta@ufrb.edu.br **Universidade Federal Recôncavo da Bahia fabianacomerlato@ufrb.edu.br Contas basin, Bahia, during the construction the highway BA-001 (Camamu and (tacaré). In order to accomplish this, the archaeological data and these domestic units will be interpreted as belonging to a diffuse system of territorial control of the landscape.

Keywords: archaeology; rural residences; 19th centurie; diffuse territorial control of the landscape; Rio de Contas basin 


\section{Introdução}

As intervenções arqueológicas realizadas no processo de licenciamento ambiental do trecho de $48,1 \mathrm{~km}$ da BA-001, entre Camamu e Itacaré, na região Baixo Sul da Bahia ${ }^{1}$, possibilitaram o estudo sistemático de vinte e quatro sítios arqueológicos (Fernandes \& Costa, 2006; Fernandes, 2007; Costa, 2008). Esse universo aponta para diferentes momentos de ocupação humana, associados a períodos pré-coloniais, coloniais e pós-coloniais. No âmbito dessas intervenções os sítios Sete Estrelas e Jeribucaçu se tornaram importantes, pois possibilitam a compreensão dos mecanismos de ocupação social da paisagem em períodos pós-coloniais no Baixo Sul da Bahia (Figura 1).

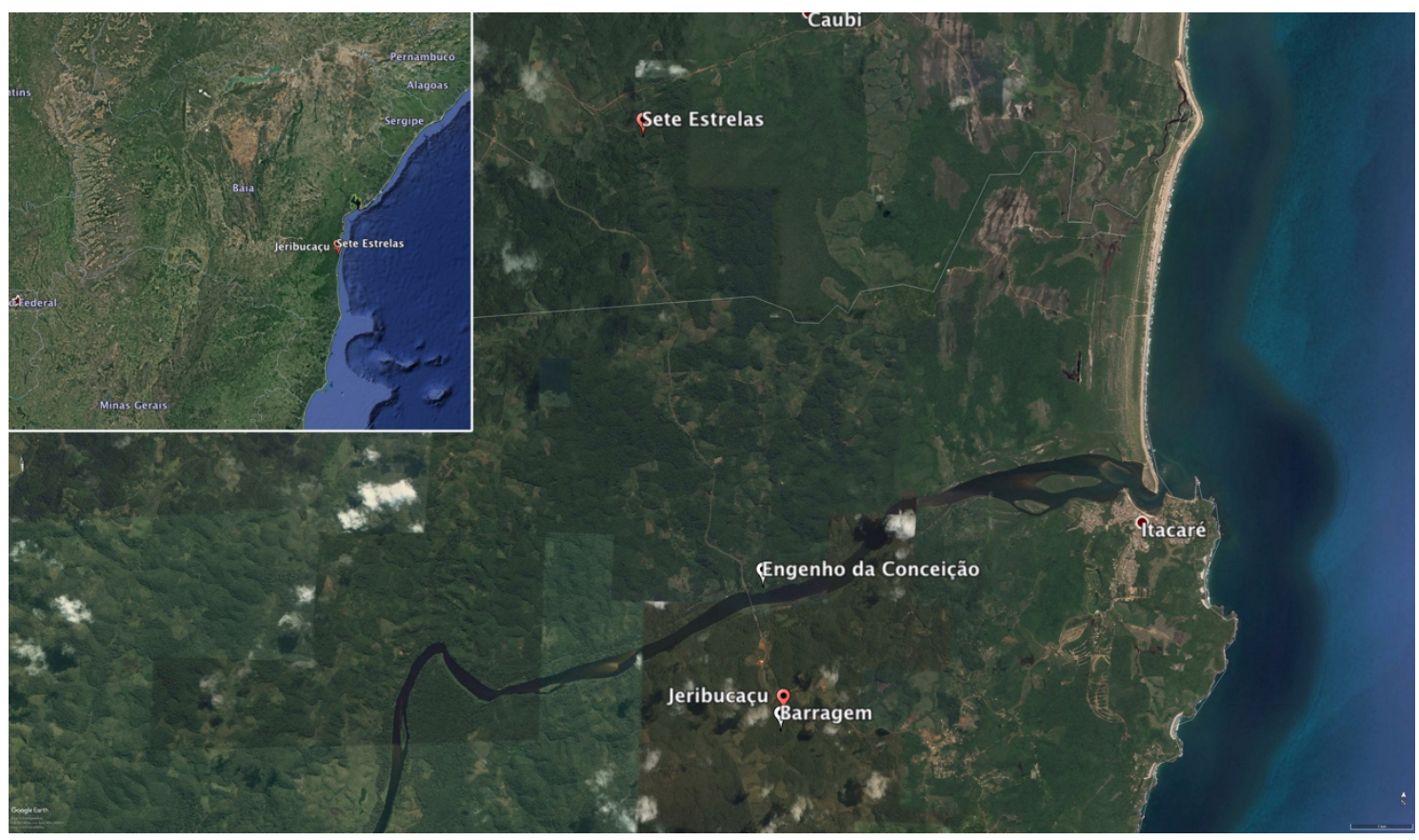

Figura 1: Mapa da Bahia, com identificação da localização dos sítios na região Baixo Sul. Na ampliação, o leito do rio de Contas, com a identificação do município de Itacaré e dos sítios Sete Estrelas e Jeribucaçu. Fonte: Google Earth, 2018.

Tratam-se de duas residências rurais localizadas na bacia do rio de Contas que, observadas em associação com contextos produtivos locais - os engenhos de açúcar e, posteriormente, as casas de farinha - permitem lançar o olhar acerca de um fenômeno que chamamos de controle territorial difuso da paisagem. Trata-se de um sistema sócio-espacial de produção e domínio da paisagem, no qual atuam diferentes agentes sociais, com interesses, posições sociais e parcelas de participação distintas. Esses agentes utilizam e mantêm o sistema a partir de uma rede de relações sociais engendrada por conveniências e afinidades, não, necessariamente, com o controle coercitivo.

\footnotetext{
${ }^{1}$ Atividades executadas a partir de convênio celebrado entre o Museu de Arqueologia e Etnologia (MAE) da Universidade Federal da Bahia (UFBA) e o, hoje, extinto Departamento de Infraestrutura de Transportes da Bahia (Derba). Os trabalhos arqueológicos foram realizados com autorização do Instituto do Patrimônio Histórico e Artístico Nacional (Iphan).
} 
No caso apresentado, esse sistema estava situado na bacia do rio de Contas e se fundamentava, essencialmente, pela produção açucareira a partir de engenhos distribuídos ao longo do rio. As unidades habitacionais, comerciais e religiosas estavam distantes das unidades produtivas e dispersas ao longo dessa paisagem, sem conformar concentrações num mesmo local. Objetivamente, compreendemos que se tratava de um sistema produtivo no qual os agentes sociais eram mutuamente interdependentes por redes de afinidades de diversas ordens (material, comercial, simbólica etc.), que possibilitavam concentração de interesses de agentes dispersos no território.

Sendo assim, esse modelo se diferencia daquele proposto por Gilberto Freyre (2012 [1933]), que figura os engenhos de açúcar como sistemas produtivos, cujas instalações como casa grande, capela, engenho e senzala estavam concentradas num mesmo espaço, onde o controle coercitivo, material e simbólico era possível.

O objetivo deste artigo é apresentar os resultados das intervenções arqueológicas de duas residências rurais do século XIX que participavam desse sistema territorial difuso e, posteriormente, interpretar os dados a luz das informações arqueológicas conhecidas para a localidade.

\section{Sítio Sete Estrelas}

O sítio Sete Estrelas está localizado na zona rural do município de Maraú, a aproximados $6 \mathrm{~km}$ do leito do rio de Contas (UTM 24L W492300 / N8427250 SAD69), situado no topo de uma colina de composição argilosa, numa área de roça de mandioca e capoeira densa, atravessado por uma estrada carroçável.

As intervenções arqueológicas nesse espaço objetivaram levantar uma amostra qualitativa do sítio para contextualização da atividade humana com relação ao tempo, espaço e tipo de ocupação. Para delimitação dos contextos arqueológicos em subsuperfície foram adotadas linhas paralelas de sondagens, com tamanho padrão de $1 \times 1$ metro, distando entre si de $10 \mathrm{em}$ 10 metros nas situações de delimitação de área de ocorrência de materiais em profundidade. Nos espaços onde foram localizados materiais ocorreu o adensamento da distribuição das sondagens para 5 em 5 metros. Foram realizadas 32 sondagens, das quais 7 apresentaram resultados positivos e 25 foram estéreis.

Como procedimento complementar de verificação de sub-superfície foi realizada uma linha de tradagem para delimitar extensão vertical e horizontal de uma mancha de descarte. Associada a observação de subsuperfície, foi demarcada a área de maior ocorrência de materiais em superfície, sejam eles estruturados ou dispersos, através de dois eixos denominados de $X$ e $Y$ (Figura 2). 


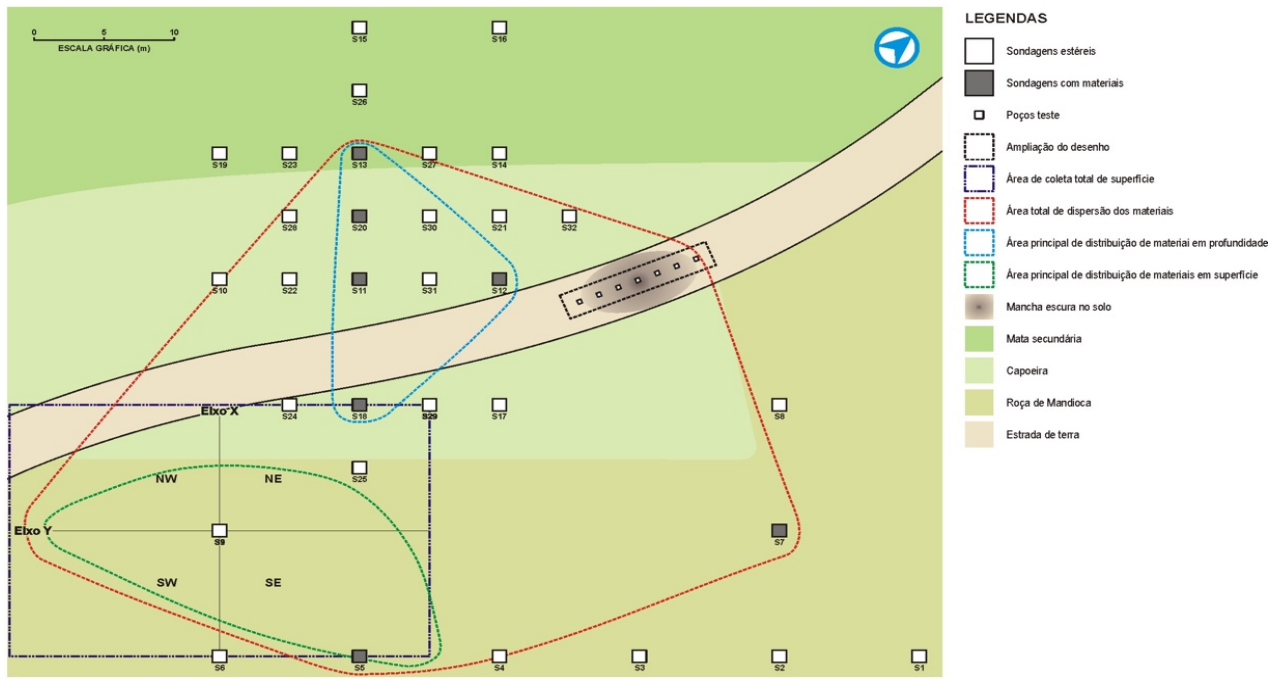

Figura 2: Planta de identificação das intervenções e contextos arqueológicos. Planta: Carlos Costa, 2007.

O conjunto artefatual exumado, após a triagem em laboratório, é de 75 fragmentos cerâmicos e 10 vítreos. As poucas faianças presentes constituem-se de dois fragmentos de shell edged, dois de motivo floral e dois de louça sem decoração (Tocchetto et all, 2001). Os outros tipos de cerâmica presentes foram fragmentos de garrafas de grês, cerâmica vitrificada, cerâmica torneada e, principalmente, cerâmica modelada sem decoração, comumente chamada de neobrasileira (Gráficos 1 e 2). Esta cerâmica sem decoração representa quase metade da amostra, em sua maioria alisada, tendo a presença de um cabo e duas asas com decoração incisa junto à borda (Figura 3). Trata-se de pequenas panelas de uso diário com a presença de fuligem nas paredes externas e borra nas internas.

As peças de vidro são todas de garrafas da cor verde escuro, em formato cilíndrico e feitas a molde. Parecem se tratar de duas garrafas de bebida alcoólica (Santos, 2005) (Figura 4).

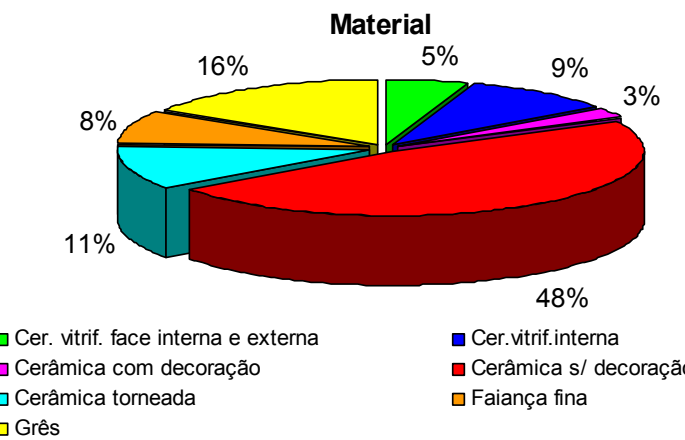

Gráfico 1: percentual dos tipos de materiais cerâmicos do sítio Sete Estrelas.

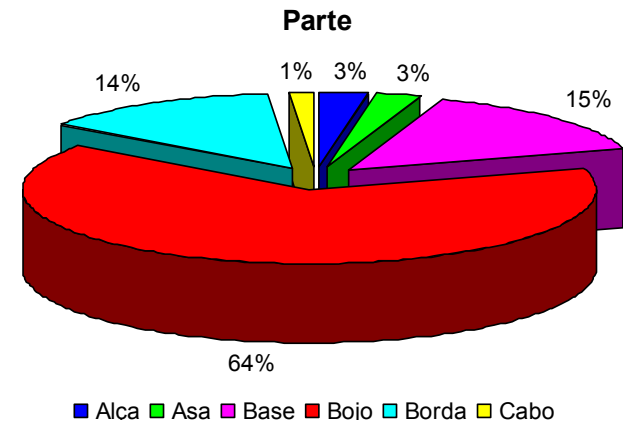

Gráfico 2: percentual das partes dos fragmentos de todos os tipos cerâmicos do sítio Sete Estrelas.

Os procedimentos de campo e laboratório adotados permitem interpretar as evidências arqueológicas - cerâmicas simples e vitrificadas, poucos vidros soprados e moldados, grês e faianças finas inglesas, forno de adobe, biofatos, mancha no solo e a distribuição desses 
materiais no espaço - como resultantes de atividades domésticas associadas a uma residência rural, ocorrida no século XIX, cujos moradores detinham baixo poder aquisitivo. Apesar do sítio se apresentar bastante perturbado por atividades agrícolas e a abertura de uma estrada carroçável por madeireiras e não terem sido localizados vestígios seguros da residência (paredes, telhas, alicerces etc.), as estruturas arqueológicas identificadas, observadas de maneira relacionadas, permitem reconhecer duas áreas funcionais do sítio: uma destinada ao trabalho ou produção, provavelmente de uma casa de farinha, haja vista a presença do forno de adobe e das bordas do assador; e outra destinada à residência, em que os materiais de uso doméstico de cozinha e mesa estiveram presentes.

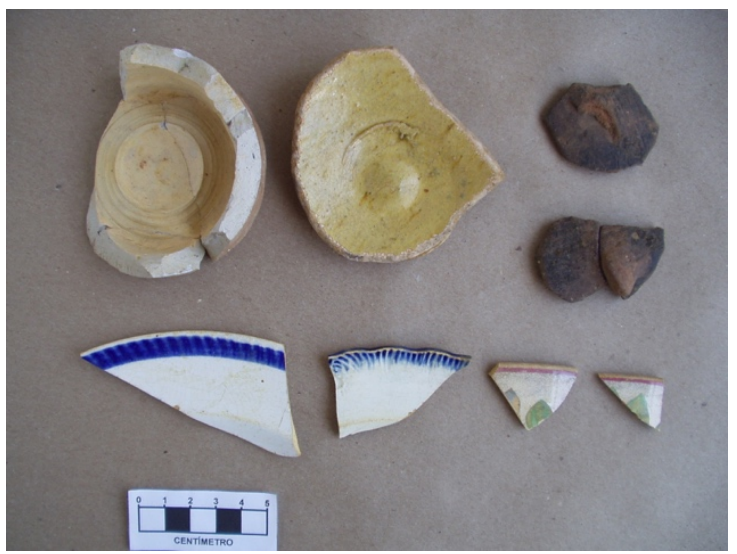

Figura 3: No alto: grês, cerâmica vitrificada e cerâmica Neo-brasileira. No baixo: faianças finas padrão shell edged e floral. Peças: SE.1, SE.42, SE.13, SE.10, SE.32, SE.45, SE.22, SE.21. Foto: Fabiana Comerlato, 2007.

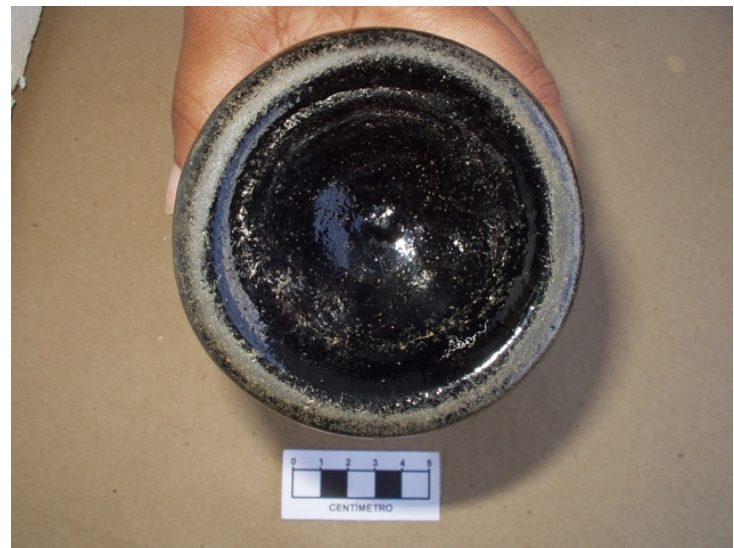

Figura 4: Base de garrafa cilíndrica, com $8 \mathrm{~cm}$ de diâmetro. Peça: SE.40. Foto: Fabiana Comerlato, 2007.

\section{Sítio Jeribucaçu}

O sítio Jeribucaçu está localizada na zona rural do município de Itacaré, a aproximadamente 1 $\mathrm{km}$ do leito do rio de Contas e 8 km do município de Itacaré (UTM 24L W494946 / N8418134 SAD69), instalado numa área de pastagem e capoeira, atravessada por uma estrada carroçável. O relevo é de inclinação suave nas margens do topo de uma colina, onde o solo tem composição argilosa.

Assim como o sítio anterior, objetivou-se com as intervenções obter uma amostra de materiais para a caracterização da ocupação. Para delimitação dos contextos em subsuperfície foram realizadas 15 sondagens de $1 \times 1$ metro, dispostas na área aleatoriamente, sobretudo nos setores delimitados por alicerces. Além disto, foram escavadas trincheiras, com largura média de $50 \mathrm{~cm}$, acompanhando o alinhamento dos alicerces, para delimitação das ocupações (Figura 5). Os procedimentos de superfície não revelaram a presença de materiais. Todas os contextos acima da cota de contra piso (contra piso, piso, paredes etc.) foram suprimidos, provavelmente por ação mecânica de tratores. Por isso, todas as evidências são de subsuperfície (Figura 6). 


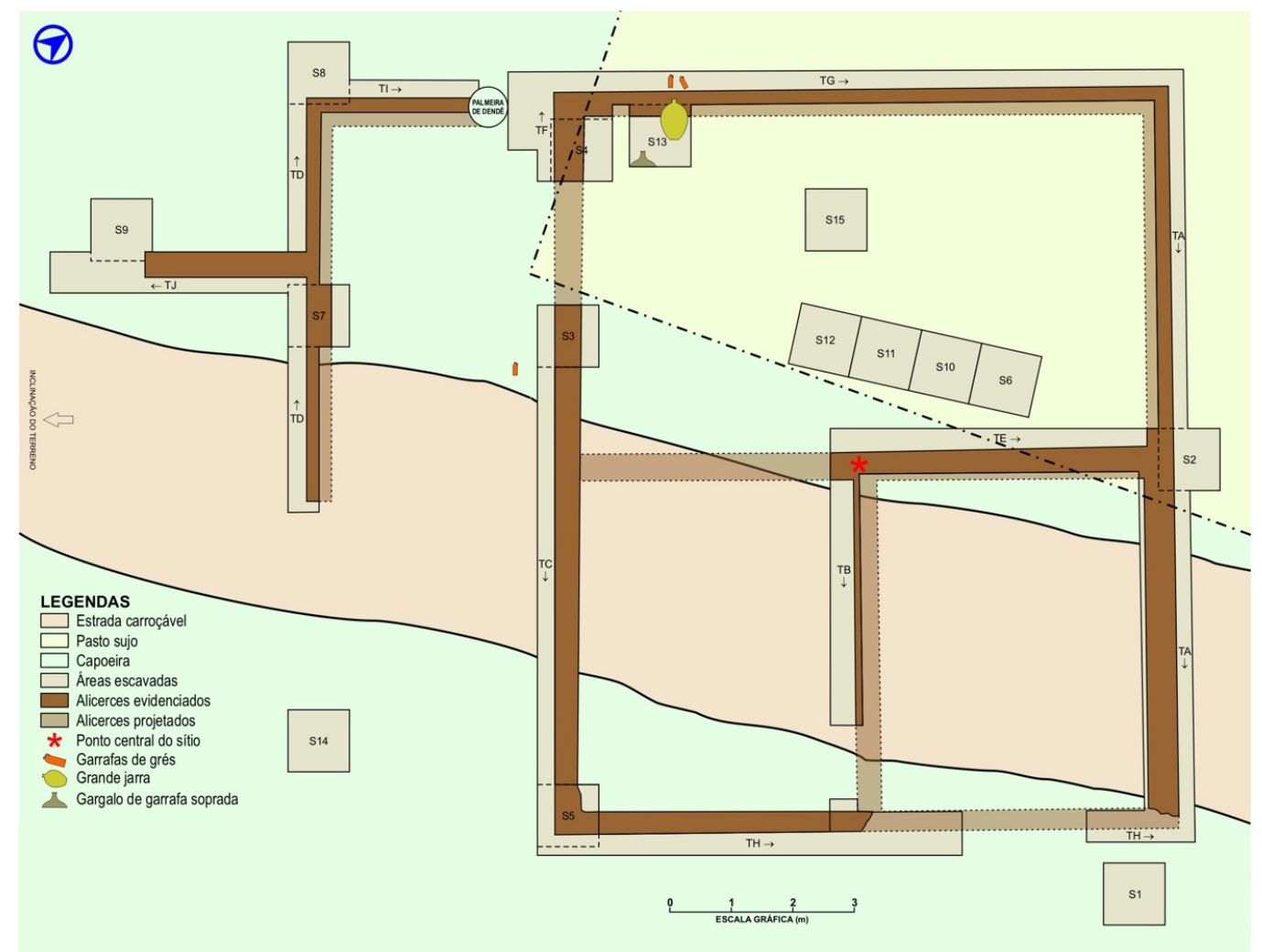

Figura 5: Planta de identificação das intervenções e contextos arqueológicos. Planta: Carlos Costa, 2007.

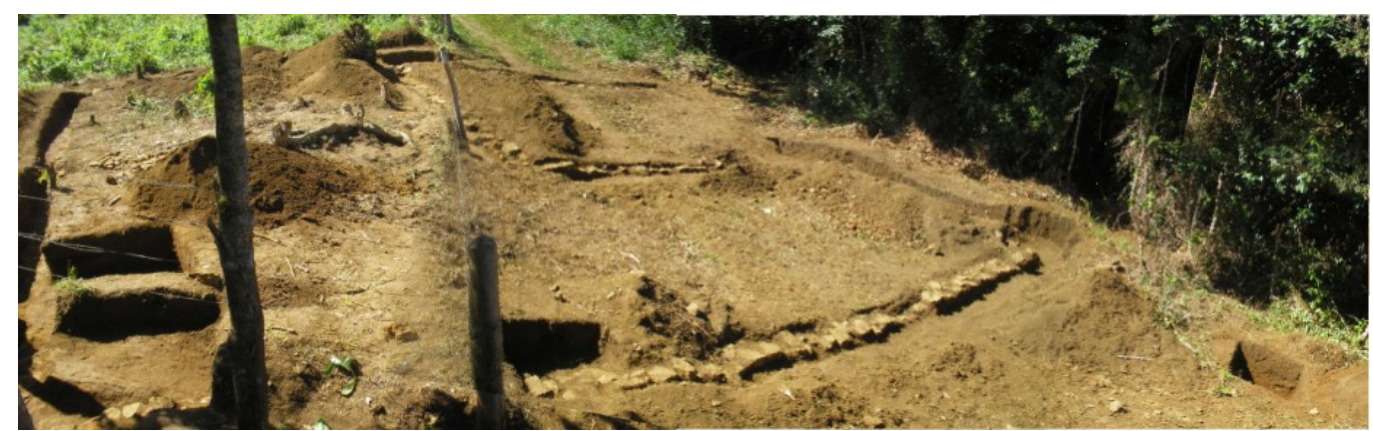

Figura 6: Vista panorâmica do sítio Jeribucaçu depois de finalizada a escavação. Foto: Carlos Costa, 2007.

Foram identificados quatro cômodos da casa, sem possibilidade de definição das suas funções. Ainda assim, a localização de garrafas de grês, uma grande jarra e a terminação de um garrafão de vidro concentrados em um destes setores sugerem que o cômodo situado no lado noroeste do sítio seja a cozinha. $O$ universo artefatual exumado aponta para os serviços residenciais de cozinha e mesa. Por fim, podemos dizer, com certa segurança, que esta ocupação ocorreu entre o segundo e terceiro quartel do século XIX, haja vista a presença de materiais que circularam comumente no território brasileiro naquele momento, após a abertura dos portos ocorrida em 1808, a exemplo de grês, faiança fina inglesa, garrafas de vidro produzidas pela técnica soprada.

A ocupação estava instalada em dois patamares, aproveitando a topografia do terreno. 0 cômodo situado a sudoeste, cujos alicerces foram identificados na sondagem 7 , encontra-se 1 
$\mathrm{m}$ mais baixo que a área principal. Apesar de existirem apenas os alicerces, as intervenções arqueológicas neste setor demonstraram que os artefatos associados a ocupação mantiveramse, em boa medida, preservados, escavados a aproximadamente $40 \mathrm{~cm}$ da superfície. Isto porque os materiais foram encontrados com fragmentos de grande tamanho e bom estado de conservação, concentrados num mesmo setor do sítio.

O material cerâmico coletado é composto, em sua maioria, de fragmentos de faiança fina e cerâmica vitrificada. Há também fragmentos de grês, porcelana, cerâmica neo-brasileira e cerâmica torneada. Algumas peças desse sítio foram restauradas: três garrafas de grês e uma jarra de cerâmica vitrificada (Figura 7).
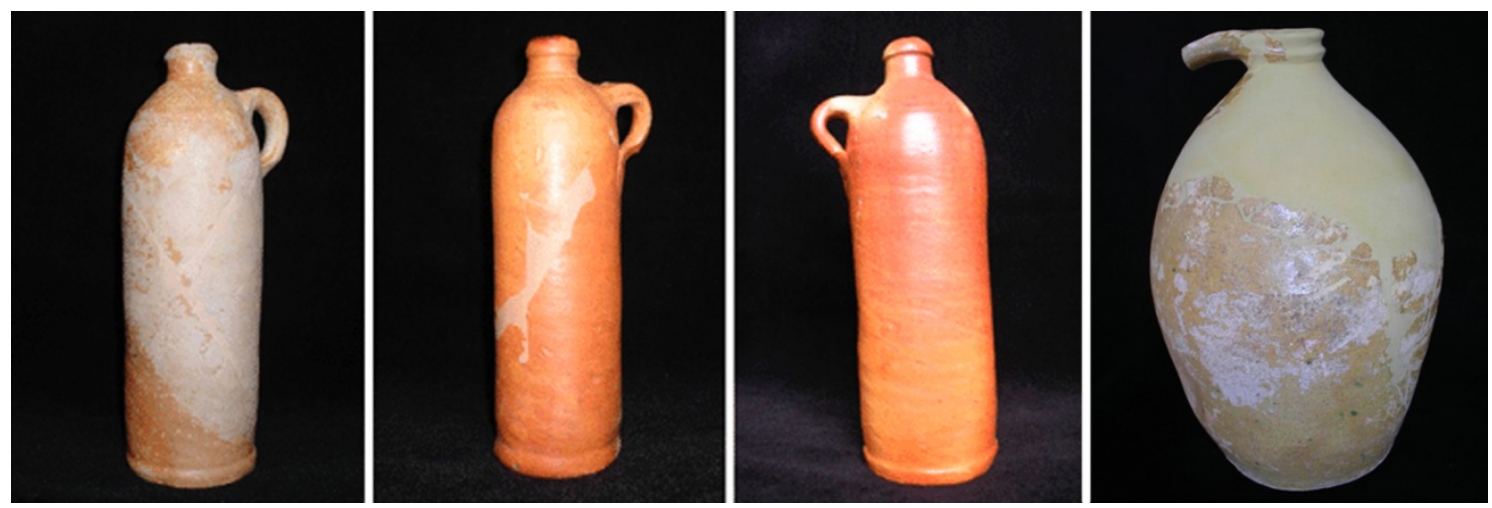

Figura 7: Peças restauradas. Três garrafas de grês com capacidades, obtidas por medida seca, de 750 g, 600 g 750 g, respectivamente, e uma grande jarra de cerâmica de torno vitrificada, com cerca de $45 \mathrm{~cm}$ de altura. Da esquerda para direita, peças JB.104, JB.103, JB.105 e JB 102. Fotos: Fabiana Comerlato, 2007.

A amostra de faiança fina é composta de 19 fragmentos, com as seguintes técnicas decorativas: louça não decorada, transfer printing / borrão, carimbada e pintada à mão livre. Os motivos representados neste conjunto de faianças são: shell edged, floral, geométrico e chinesa (gráficos 3 e 4). As formas identificadas foram de pratos, recipientes côncavos e xícaras. Apenas duas peças apresentaram no frete a marca de fabricantes estrangeiros (Tocchetto et all, 2001) (Figura 8).

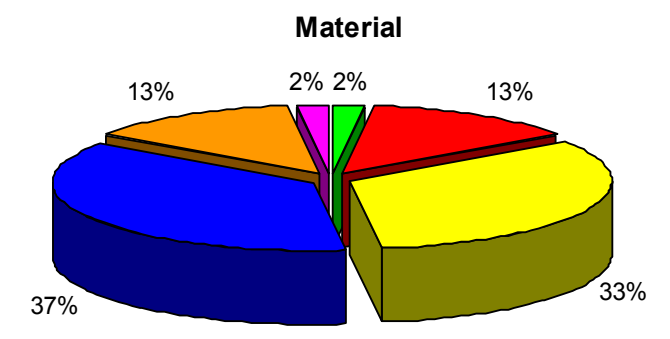

$\square$ Cerâmica

- Faiança fina

$\square$ Cerâmica torneada $\square$ Cerâmica vitrificada

$\square$ Grês $\quad \square$ Porcelana

Gráfico 3: Percentual dos tipos de materiais cerâmicos do sítio Jeribucaçu.

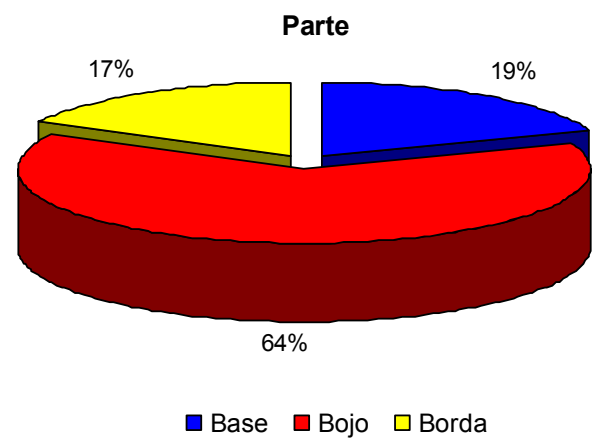

Gráfico 4: Percentual das partes dos fragmentos de todos os tipos cerâmicos do sítio Jeribucaçu. 

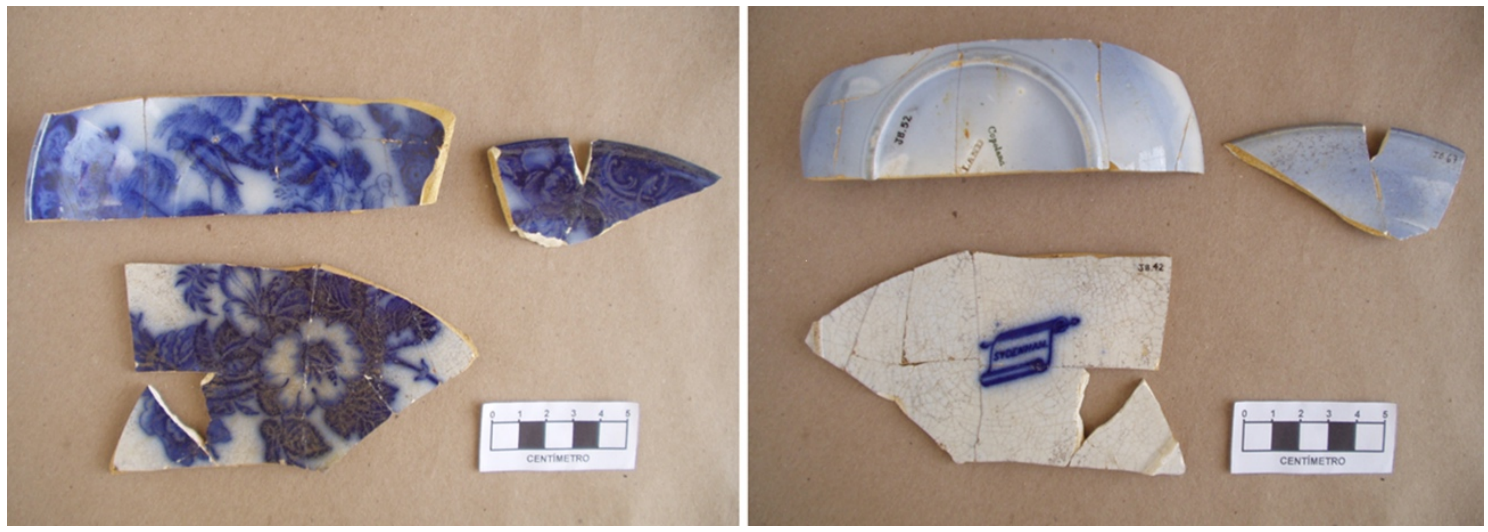

Figuras 8: Faiança fina, transfer printing / borrão. À esquerda face interna e à direita face externa. Peças JB.52, JB.67 e JB.42. Foto: Fabiana Comerlato, 2007.

Os fragmentos vítreos mais significativos foram uma garrafa cilíndrica, uma terminação de garrafão, bases de garrafas cilíndricas de cor preta e uma garrafa retangular com inscrições em uma de suas paredes (Santos, 2005) (gráficos 5, 6, 7 e 8; figura 9).

\section{Parte}

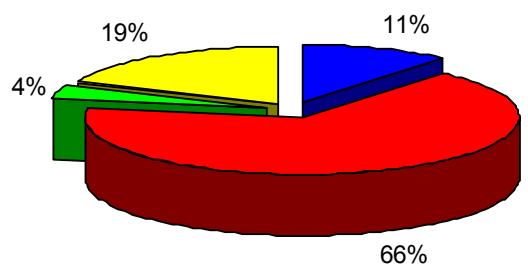

$\square$ Base $\square$ Corpo $\square$ Inteira $\square$ Terminação

Gráfico 5: Percentual das partes dos vidros do sítio Jeribucaçu.

\section{Forma do recipiente}

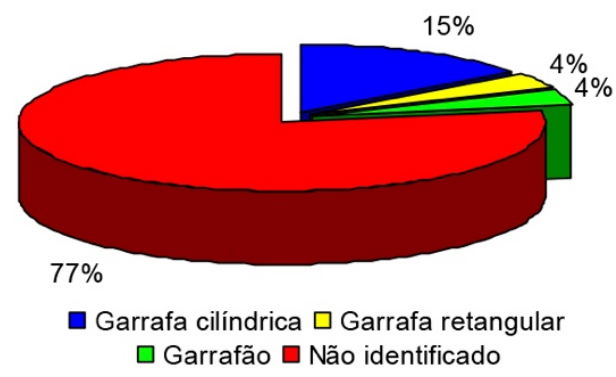

Gráfico 7: Percentual das formas de recipientes dos vidros do sítio Jeribucaçu.
Técnica

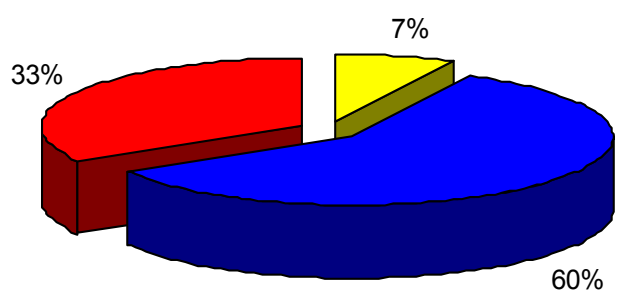

$\square$ Molde $\square$ Não identificada $\square$ Sopro

Gráfico 6: Percentual das técnicas de confecção dos vidros do sítio Jeribucaçu.

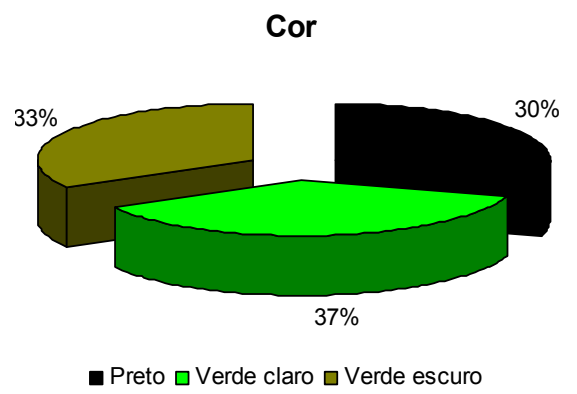

Gráfico 8: Percentual das cores dos vidros do sítio Jeribucaçu. 


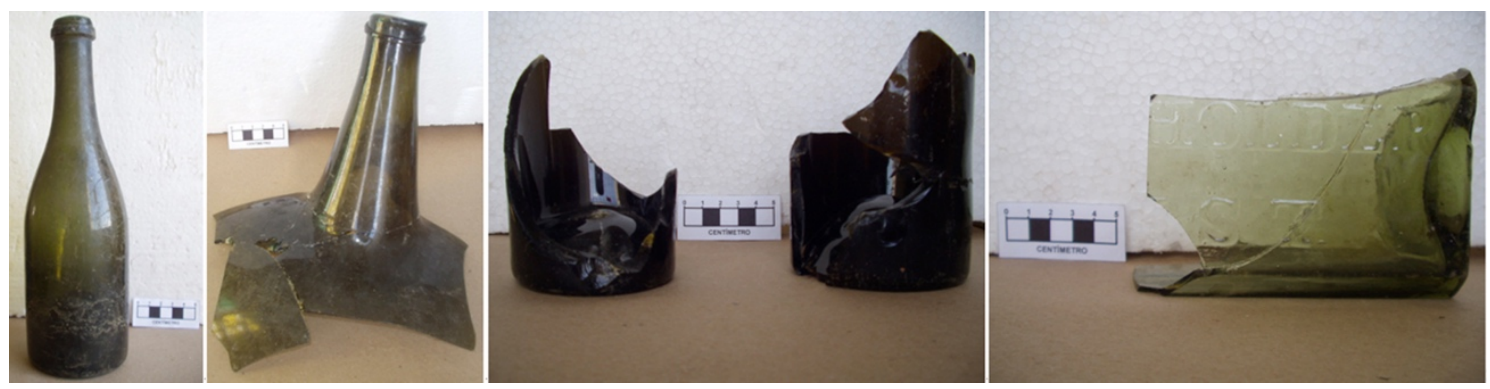

Figuras 9: Da esquerda para direita: garrafa cilíndrica com terminação champanhe e capacidade $400 \mathrm{ml}$ (medida seca), peça JB.16; garrafão de vidro, peça JB.49; bases de garrafas cilíndricas de vinho do Porto, peças JB.21 e JB.81; garrafa retangular com inscrições, peça JB.88. Fotos: Fabiana Comerlato, 2007.

As peças metálicas encontradas foram em número de dezesseis, constando de chaves, facas, botões, lâminas, dentre outros (Costa, 2005).

Os dados compulsados indicam que o sítio Jeribucaçu refere-se a residência rural de médio porte, com $17 \times 12$ metros (pouco mais de $200 \mathrm{~m}^{2}$ ) e 4 cômodos, do segundo e terceiro quartel do século XIX. O partido construtivo e os materiais móveis indicam um padrão de consumo mais elevado que aquele verificado para o sítio Sete Estrelas. A disposição na paisagem coloca esse sítio na bacia do rio de Contas, perto dos engenhos. Isto sugere que o proprietário da residência se instalou de maneira estratégica, próximo das vias de circulação e escoamento de produtos, por terra e por água, no eixo comercial da região.

Além dos contextos identificados no espaço específico do sítio, próximo a essa ocupação, a \pm 120 metros, foi registrada uma barragem com cerca de $30 \mathrm{~m}$ de comprimento, feita com grandes pedras circulares unidas por argamassa de argila vermelha (UTM 24L W494916 / N8417860 SAD69). Numa das extremidades existe uma intervenção recente que, segundo os moradores locais, foi realizada na década de 70 do século $X X$ e refere-se a uma pequena comporta de abertura para controle de passagem de água, que servia a um engenho localizado no meio da mata marginal à estrada.

\section{Considerações Finais}

Os sítios Sete Estrelas e Jeribucaçu ilustram um episódio relevante do histórico de ocupação territorial do Baixo Sul da Bahia, no século XIX. Tratam-se de ocupações que, embora tragam em si elementos que apontam para uma tradição europeia (a exemplo das construções e das faianças), são fundamentalmente adaptadas e adequadas a realidade local.

O sítio Sete Estrelas, interpretado como uma casa modesta, está situado na zona rural, num setor da paisagem com menor rede de acesso e distante dos eixos de circulação de informação e comerciais da região. Nele foram identificados o espaço da unidade habitacional e uma casa de farinha, o que indica uma produção local de subsistência.

Já o sítio Jeribucaçu representa uma residência mais estruturada, provavelmente com proprietários com maior poder aquisitivo, com $\pm 200 \mathrm{~m}^{2}$ e, pelo menos, quatro cômodos. Diferente do exemplo anterior, essa residência rural estava estrategicamente localizada no 
eixo de circulação de informações, mercadorias e serviços da região. Próximo dela está o rio de Contas - onde se situavam os engenhos ${ }^{2}$ e se conformava como rota que permitia acesso ao mar - e a estrada que ligava Itacaré a llhéus, principais áreas urbanas da região.

A associação desses sítios com outras unidades reconhecidas na região, em especial as plantações de cana de açúcar, cidades e engenhos se nos afigura reveladora de um padrão de segregação sócio-espacial ocorrida neste setor do Baixo Sul da Bahia. A residência modesta está distante das áreas decisórias de Itacaré. A residência mais abastada está privilegiadamente instalada no polo de circulação de informações, produção e serviços, próximos das cidades, das áreas produtivas, das vias de transporte por água e terra.

Enfim, falamos de relações espaciais ocorridas numa paisagem ampliada, difusa, que não poderiam ser compreendidas de maneira isolada. O controle territorial difuso, do qual entendemos que essas residências integravam, diz respeito a congregação, na bacia do rio de Contas, de unidades diferentes, mutuamente interdependentes, com interesses distintos, com indivíduos que trabalhavam, produziam, comercializavam, detinham a propriedade ou somente obtinham lucros. Não se tratava de um senhor de engenho com controle total da produção, senão de um sistema sócio-produtivo, com a participação de agentes distintos que atuavam na paisagem regional através de redes de interesses e afinidades, portanto, com controle difuso da produção.

\section{Referências}

COSTA, C. A. S. 2005. Materiais construtivos do sítio da primeira Catedral do Brasil: modelos de estudo para telhas, tijolos, cravos e azulejos aplicados aos materiais do sítio da antiga igreja da Sé, Salvador, Bahia. CLIO - Série Arqueológica, Recife, v. 2 (19), pp. 43-78.

COSTA, C. A. S. 2008. Relatório final do salvamento e levantamento arqueológico complementar na rodovia BA-001 (trecho BR-030 - Itacaré). Salvador, MAE/UFBA.

FERNANDES, H. L. A; COSTA, C. A. S. 2009. Arqueologia do baixo sul da Bahia: condicionantes espaciais na implantação de engenhos de açúcar. Revista de Arqueologia, Belém, v. 22 (2), pp. 137156.

FERNANDES, H. L. A; COSTA, C. A. S. 2006. Relatório final do diagnóstico e levantamento arqueológico na rodovia BA-001 (Camamu-Itacaré). Salvador: MAE/UFBA.

FERNANDES, H. L. A. 2007. Relatório final do resgate e monitoramento arqueológico na rodovia BA001 (Camamu - BR-030). Salvador: MAE/UFBA.

FREYRE, G. 2012 [1933]. Casa grande e senzala, 9ạ ed. São Paulo: Global.

SANTOS, P. A. G. 2005. Contentores de bebidas alcoólicas: usos e significados na Porto Alegre oitocentista. Dissertação (Mestrado em Arqueologia). Programa de Pós-Graduação em História da Pontifícia Universidade Católica do Rio Grande do Sul, Porto Alegre, Brasil.

TOCCHETTO, F. B.; SYMANSKI, L. C. P.; OZÒRIO, S. R.; OLIVEIRA, A. D. T; CAPPELLETTI, A. M. 2001. A faiança fina em Porto Alegre: vestígios arqueológicos de uma cidade. Porto Alegre: EU / Secretaria Municipal da Cultura.

\footnotetext{
${ }^{2}$ Tal como o Engenho Conceição ou Engenho de Rio de Contas, situado a $1 \mathrm{~km}$, que também foi alvo de intervenções arqueológicas (Fernandes \& Costa, 2009).
} 